\title{
A Review of Options for Treating Sialorrhea in Amyotrophic Lateral Sclerosis
}

\author{
Paolo Banfi MD, Nicola Ticozzi MD, Agata Lax MD, Giulia Andrea Guidugli MD, \\ Antonello Nicolini MD, and Vincenzo Silani MD
}

\author{
Introduction \\ Purpose of This Review \\ Search Strategy and Selection Criteria \\ Anticholinergic Drugs \\ BoNT (Botox) \\ Radiotherapy \\ Surgical Treatment
}

\begin{abstract}
Sialorrhea or drooling represents quite a common problem in patients with amyotrophic lateral sclerosis (ALS). In this review, we describe the possible treatments for this issue. Current medical management is not always effective: anticholinergic drugs (atropine, glycopyrrolate, amitriptyline, hyoscyamine, and transdermal scopolamine) are often used, but there is very little evidence of their effectiveness in patients with ALS. More invasive treatments, such as botulinum toxin injections and/or radiation therapy in the salivary glands, can be considered when anticholinergic drugs are not effective. In this review, we also explore the possible surgical options for treatment of sialorrhea. Although no specific studies have been conducted on patients with ALS, surgical therapies might represent a valid option for treatment of sialorrhea since there is no tachyphylaxis or need for repeated therapeutic sessions. Key words: amyotrophic lateral sclerosis; salivary glands; sialorrhea; drooling; aspiration pneumonia; botulinum toxin; radiotherapy; surgical intervention; quality of life. [Respir Care 2015;60(3):446-454. ( 2015 Daedalus Enterprises]
\end{abstract}

\section{Introduction}

Amyotrophic lateral sclerosis (ALS) is a progressive and fatal neurodegenerative disease affecting motor neu-

\footnotetext{
Drs Banfi and Lax are affiliated with the Don Carlo Gnocchi Foundation, Milan, Italy. Drs Ticozzi and Silani are affiliated with the Unit of Neurology and Laboratory of Neuroscience, Istituto Auxologico Italiano, Istituto di Ricovero e Cura a Carattere Scientifico, Milan, Italy and the Department of Pathophysiology and Transplantation, Dino Ferrari Center, Università degli Studi di Milano, Milan, Italy. Dr Guidugli is affiliated with the San Giuseppe Hospital, Ospedale Classificato, Istituto di Ricovero e Cura a Carattere Scientifico Multimedica, Milan, Italy. Dr Nicolini is affiliated with the Respiratory Diseases Unit, Hospital of Sestri Levante, Genoa, Italy.
}

The authors have disclosed no conflicts of interest. rons in the anterior horn of the spinal cord, the brainstem, and the motor cortex. It is clinically characterized by progressive weakness, usually leading to death by respiratory insufficiency within 3-5 y. ${ }^{1}$ Bulbar symptoms at ALS onset are observed in up to $30 \%$ of patients, and almost all patients have a bulbar involvement at later stages of the disease. ${ }^{1,2}$ Dysphagia often leads to dehydration, malnutrition, choking, and pulmonary aspiration. Malnutrition is an independent risk factor for death in ALS. ${ }^{3,4}$ The in-

\footnotetext{
Correspondence: Paolo Banfi MD, Don Carlo Gnocchi Foundation, Istituto Palazzolo, Via Palazzolo 21, 20162 Milan, Italy. E-mail: pabanfi@ dongnocchi.it.
}

DOI: $10.4187 /$ respcare. 02856 
volvement of upper motor neurons causes a set of symptoms known as pseudobulbar palsy, which is characterized by spasticity of the bulbar muscles (which control speech, chewing, and swallowing) and emotional lability (pathologic laughing and crying). In addition, loss of motor neurons in the spinal cord causes muscular weakness and atrophy, leading in turn to progressive respiratory dysfunction, labored communication, and decreased voluntary as well as reflexive coughing. ${ }^{5-8}$

In ALS, sialorrhea is caused mostly by a decreased ability to swallow secretions (not by increased saliva production) due to tongue spasticity, orofacial and palatinolingual muscle control failure, facial weakness, and inability to maintain oral and buccal competence. ${ }^{9} 10$ The progressive weakness of facial muscles and difficulty in swallowing saliva leads to drooling. ${ }^{11-13}$ About half of all patients affected by ALS report significant sialorrhea or drooling at some point during the course of the disease, and $\sim 20 \%$ of them have moderate-to-severe symptoms. ${ }^{14}$ There are different scales for the assessment of sialorrhea. The revised Amyotrophic Lateral Sclerosis Functional Rating Scale, a widely used and validated instrument to monitor disease progression in ALS, contains 3 items assessing the function of bulbar muscles, including one evaluating sialorrhea. ${ }^{15}$

In 2013, Abdelnour-Mallet et al ${ }^{16}$ attempted to evaluate the effectiveness of 2 other scales: the Oral Secretion Scale (designed for the evaluation of hypersialorrhea in ALS) and the Sialorrhea Scoring Scale (initially developed for Parkinson's disease). Although both scales have a high inter-rater and intra-rater reliability, there are some limitations. The Oral Secretion Scale is not designed to evaluate the effectiveness of invasive treatments for hypersialorrhea, whereas the Sialorrhea Scoring Scale does not predict tolerance to noninvasive ventilation (NIV) in ALS patients. Salivary secretion in healthy adults is $\sim 1.2 \mathrm{~L} / \mathrm{d}$. During unstimulated salivation, $69 \%$ of saliva is contributed by the submandibular glands, $26 \%$ by the parotid gland, and $5 \%$ by the sublingual glands. During stimulated salivation, the parotid gland contribute $66 \%$ of the total flow. ${ }^{17}$ The submandibular gland, a mixed but mostly serous gland, is responsible for stimulated and unstimulated saliva production, whereas the parotid gland, a purely serous gland, secretes saliva mainly during mastication. The sublingual gland is purely mucous. Excessive amounts of saliva significantly decrease quality of life by impairing speech production and lung function. Patients may also experience difficulties with NIV and in sleeping in a reclined position because of saliva aspiration.

The increase in mucous secretions in the throat and lungs, the inability to swallow saliva, and the cough impairment due to progressive weakness and diaphragm and respiratory muscle fatigue usually lead to an increased risk of aspiration pneumonia. ${ }^{8,18-21}$ Drooling also causes der-
Table 1. Inclusion Criteria for the Four Key Questions

\begin{tabular}{|c|c|c|c|c|}
\hline & $\begin{array}{l}\text { Question } \\
1\end{array}$ & $\begin{array}{l}\text { Question } \\
2\end{array}$ & $\begin{array}{l}\text { Question } \\
3\end{array}$ & $\begin{array}{c}\text { Question } \\
4\end{array}$ \\
\hline \multicolumn{5}{|l|}{ Study design } \\
\hline Retrospective cohort & Yes & Yes & Yes & \\
\hline Retrospective case control & Yes & Yes & Yes & Yes \\
\hline $\begin{array}{l}\text { Prospective cohort or } \\
\text { clinical trial }\end{array}$ & Yes & Yes & Yes & Yes \\
\hline \multicolumn{5}{|l|}{ Outcomes } \\
\hline $\begin{array}{l}\text { Clinical characteristics of } \\
\text { range of symptoms }\end{array}$ & & & Yes & Yes \\
\hline Duration of symptom relief & & & Yes & Yes \\
\hline \multicolumn{5}{|c|}{$\begin{array}{l}\text { Did the studies cited answer the following questions? Question 1: Which area was treated? } \\
\text { Question 2: What therapy was used (and at which dosage level)? Question 3: How long did } \\
\text { the effect last? Question 4: Have side effects been reported? }\end{array}$} \\
\hline
\end{tabular}

matologic problems, such as facial irritation and skin excoriation. ${ }^{5}$ Although pulmonary aspiration syndromes are often misdiagnosed in patients with ALS, they are associated with a high mortality. ${ }^{8}$ In a cohort of 40 consecutive patients with ALS, Sorenson et al ${ }^{18}$ observed the occurrence of aspiration pneumonia in 5 cases (13\%). In an autopsy cohort of patients with ALS, Kurian et $\mathrm{al}^{22}$ found a similar number of occurrences, with aspiration pneumonia being listed as the cause of death in $11 \%$ of cases, bronchopneumonia in $41 \%$, and respiratory failure in $9 \%$. Death was directly attributable to motor neuron disease in $11 \%$ of cases, cardiac causes in $14 \%$, malignancies in $5 \%$, and other causes in the remaining 9\% of patients. ${ }^{22}$ Excessive drooling also limits tolerance of NIV, which has been consistently shown to increase the life expectancy and quality of life of patients with ALS. ${ }^{23-33}$ Thus, a successful management of sialorrhea may prolong NIV tolerance in ALS, ${ }^{34}$ resulting in enhanced survival. ${ }^{35}$

\section{Purpose of This Review}

We present a systematic review of studies describing the various possible treatments for sialorrhea in subjects with ALS, attempting to assess the effectiveness of these therapies in improving quality of life and diminishing the risks due to excessive drooling and to evaluate their side effects and long-term efficacy.

\section{Search Strategy and Selection Criteria}

After defining criteria for study selection (Table 1) and for validity assessment, we searched MEDLINE for studies published from January 1994 through November 2013 using the following MeSH terms: sialorrhea, drooling, ptyalism, anticholinergic drug, neuromuscular agents, botulinum toxin (BoNT), radiotherapy, surgical intervention 
Table 2. Side Effects of Anticholinergic Drugs in Amyotrophic Lateral Sclerosis

\begin{tabular}{|c|c|c|c|}
\hline Anticholinergic Drug & Mode of Administration & Recommended Dose & Side Effects \\
\hline Atropine & Eye drops & $1-2$ drops 4 or 6 times/d & $\begin{array}{l}\text { Sensitivity to bright light, dry mouth, blurred vision, irregular } \\
\text { heartbeat, mental confusion, difficulty urinating }\end{array}$ \\
\hline Amitriptyline & Tablet & $25-450 \mathrm{mg}$ at bedtime & $\begin{array}{l}\text { Constipation, drowsiness, dry mouth, dizziness, tiredness or } \\
\text { sleepiness, feeling faint when getting up, increased blood } \\
\text { pressure, fast/racing heart, palpitation, heart attack, stroke, } \\
\text { irregular or slow heart beats, very low blood pressure, } \\
\text { feeling or being sick, diarrhea, increased need to urinate }\end{array}$ \\
\hline Scopolamine & Transdermal patch & $0.5 \mathrm{mg}$ every $3 \mathrm{~d}$ & Pupillary dilatation, skin reaction, urinary retention \\
\hline Hyoscyamine sulfate & Tablet or elixir & Tablet or elixir 4 or 6 times/d & $\begin{array}{l}\text { Diarrhea, confusion, hallucinations, tachycardia or uneven } \\
\text { heart rate, drowsiness, blurred vision, nausea, constipation, } \\
\text { problems with urination, dry mouth }\end{array}$ \\
\hline Diphenhydramine & Tablet & $25-50 \mathrm{mg} 3$ times/d & Sleepiness, fatigue, dizziness, dry mouth, difficulty urinating \\
\hline Oxitropium bromide & Aerosol & $1.5 \mathrm{mg}$ twice daily & $\begin{array}{l}\text { Dry mouth, cough, hoarseness, urinating less than usual or } \\
\text { not at all, stuffy nose, nosebleed, fast heart rate }\end{array}$ \\
\hline Glycopyrrolate & Tablet & $1-2 \mathrm{mg} 3$ times/d & $\begin{array}{l}\text { Blurred vision, constipation, decreased sweating, dizziness, } \\
\text { drowsiness, dry mouth, pupillary dilatation, nausea }\end{array}$ \\
\hline
\end{tabular}

AND parotid, submandibular glands, salivary glands, amyotrophic lateral sclerosis, motor neuron disease, and spinal cord disease. Only studies on human subjects with ALS published in English were included. Case reports, reviews, editorials, and letters were excluded.

The literature review was focused on answering the following key questions: anatomic targets and therapeutic doses of treatments for sialorrhea, long-term efficacy of treatments, and reported side effects of treatments. AN, NT and GAG independently reviewed the full texts of articles meeting eligibility criteria based on their abstracts (see Table 1).

\section{Anticholinergic Drugs}

Self-reported data from the ALS CARE Program (www. outcomes-umassmed.org/als, accessed March 21, 2014) suggest that $>70 \%$ of patients with ALS may benefit from treatment with anticholinergic medications (atropine eye drops [1-2 drops 4 or 6 times/d], glycopyrrolate [1-2 $\mathrm{mg} 3$ times/d], amitriptyline [25-50 $\mathrm{mg}$ at bedtime], scopolamine transdermal patch $[0.5 \mathrm{mg}$ every $3 \mathrm{~d}]$, hyoscyamine sulfate [0.125- 0.25 tablet or elixir 4 or 6 time/d], and/or diphenhydramine [25-50 mg 3 time/d]) (Table 2). There are very few clinical studies evaluating the effectiveness of these drugs on patients with ALS in a systematic fashion. ${ }^{36,37} \mathrm{~A}$ recent study by McGeachan et al ${ }^{38}$ suggests that scopolamine patches are the most effective anticholinergic drugs for management of sialorrhea in ALS, reporting a positive response in $85 \%$ of treated subjects. However, the authors noticed that about half of these subjects also required additional therapies and that $20 \%$ had to discontinue the scopolamine patches, mostly because of skin reactions. ${ }^{38}$ Orally administered anticholinergic drugs are often interrupted due to systemic side effects, such as sedation and delirium, which are especially common in elderly patients. ${ }^{39}$ Anticholinergic drugs can also cause thickening of mucous secretions in the throat and lungs, which is a far worse and more severe complication than drooling. ${ }^{14}$ Pupillary dilatation, skin reactions, and urinary retention are also minor adverse effects of scopolamine skin patches. In a cohort of 30 subjects with chronic neurologic diseases and persistent drooling, Mato et al ${ }^{40}$ reported a discontinuation rate for scopolamine patches of $13 \%$. Cooper-Knock et al ${ }^{23}$ reported a case of treatmentresistant sialorrhea in a patient with bulbar ALS. In this patient, the administration of subcutaneous glycopyrrolate (600 $\mu \mathrm{g}$ of glycopyrrolate over $12 \mathrm{~h}$ via a syringe driver) was proven to be effective without significant side effects, also achieving a greater tolerance for NIV at night. Notwithstanding this isolated finding, nearly one third of treated patients do not respond to anticholinergic drugs, and even in the presence of an adequate response in the earlier phases of the disease, for a majority of patients, these medications are often not a safe or sustainable therapy for drooling. ${ }^{14,41}$ Additionally, all anticholinergic drugs are contraindicated in the presence of heart diseases, glaucoma, pyloric stenosis, prostatic hypertrophy, and hepatic and/or renal insufficiency, and particular care must be taken in elderly patients, thus limiting their widespread adoption for the treatment of sialorrhea in ALS.

\section{BoNT (Botox)}

Patients with ALS or other neurodegenerative disorders (such as Parkinson's disease) who do not improve and/or have serious side effects with anticholinergic drugs may benefit from injections of BoNT under ultrasound guidance into the parotid and submandibular glands. BoNT, commonly known as Botox, improves sialorrhea by reduc- 
Table 3. Summary of Studies Concerning Botulinum Toxin Use in Subjects With Amyotrophic Lateral Sclerosis

\begin{tabular}{|c|c|c|c|c|c|c|c|}
\hline Reference & Study Design & $\begin{array}{l}\text { No. of } \\
\text { Cases }\end{array}$ & $\begin{array}{l}\text { Botox } \\
\text { Type }\end{array}$ & Total Dose (U) & $\begin{array}{l}\text { Parotid } \\
(\mathrm{U})\end{array}$ & $\underset{(\mathrm{U})}{\text { Submandibular }}$ & $\begin{array}{l}\text { Duration of } \\
\text { Effect (mo) }\end{array}$ \\
\hline Jackson et al ${ }^{36,41}$ & $\begin{array}{l}\text { Prospective randomized double-blind } \\
\text { placebo-controlled }\end{array}$ & 18 & $\mathrm{~B}$ & NeuroBloc, 2,500 & 500 & 750 & 3 \\
\hline Verma and Steele ${ }^{39}$ & Prospective open-label & 8 & A & Botox, 15-45 & $7.5-22.5$ & None & 2.5 \\
\hline Gilio et $\mathrm{al}^{43}$ & Prospective open-label & 26 & A & $\begin{array}{l}\text { Botox, } 20-40 \\
\text { Dysport, } 60-120\end{array}$ & $\begin{array}{l}10-20 \\
30-60\end{array}$ & None & 0.5 \\
\hline Contarino et $\mathrm{al}^{44}$ & Prospective open-label & 9 & B & NeuroBloc, 2,500 & 1,000 & 250 & 3 \\
\hline Guidubaldi et a ${ }^{46}$ & $\begin{array}{l}\text { Prospective randomized cross-over } \\
\text { double-blind }\end{array}$ & 7 & $\mathrm{~A} / \mathrm{B}$ & Dysport, 250 & 100 & 25 & $2.5-3$ \\
\hline Anagnostou et $\mathrm{al}^{47}$ & Prospective randomized double-blind & 10 & A & Botox, 40 & 20 & None & - \\
\hline Costa et $\mathrm{al}^{48}$ & Prospective open-label & 15 & $\mathrm{~B}$ & NeuroBloc, 2,500 & 1,000 & 250 & $>3$ \\
\hline Scott et $\mathrm{al}^{49}$ & Prospective open-label & 6 & A & Botox, 20-60 & $10-30$ & None & - \\
\hline Giess et al ${ }^{50}$ & Prospective open-label & 5 & A & Botox, 30-82 & $30-72$ & 5 & $>2.5$ \\
\hline Møller et al ${ }^{51}$ & Prospective open-label & 7 & A & Botox, 80-140 & $25-40$ & $15-30$ & - \\
\hline Manrique $^{52}$ & Prospective open-label & 5 & A & Botox, 100 & 20 & 30 & $3-4$ \\
\hline Lipp et $\mathrm{al}^{53}$ & $\begin{array}{l}\text { Prospective double-blind placebo- } \\
\text { controlled }\end{array}$ & 12 & A & Dysport, $37.5-150$ & $18.75-75$ & None & 3 \\
\hline Porta et $\mathrm{al}^{54}$ & Prospective open-label & 4 & A & Botox, 50-100 & $15-40$ & $10-15$ & $4-7$ \\
\hline
\end{tabular}

ing the release of acetylcholine at the neurosecretory junction. In Table 3, we present the most relevant studies concerning the use of BoNT in the treatment of sialorrhea in ALS. ${ }^{39,41-50}$ These studies used different BoNT serotypes $\left(\mathrm{A}^{39,42,43,45-47,49-54}\right.$ and $\left.\mathrm{B}^{23,41,44-46,48}\right)$, treatment regimens, and routes of administration (direct or transductal approach) with varying outcome measures. A typical regimen is the administration of a total dose of $250 \mathrm{U}$ of BoNT-A: $100 \mathrm{U}$ diluted in $0.4 \mathrm{~mL}$ of saline injected into 2 sites of each parotid gland and $25 \mathrm{U}$ diluted in $0.1 \mathrm{~mL}$ of saline injected into a single site of each submandibular gland. Another common approach is the injection of total dose of 2,500 U of BoNT-B, again subdivided into 2 sites of injection for each parotid gland $(1,000 \mathrm{U}$ in $0.4 \mathrm{~mL}$ of saline) and a single site of injection for each submandibular gland $(250 \mathrm{U}$ in $0.1 \mathrm{~mL}$ of saline). Sialorrhea is reduced $3-7 \mathrm{~d}$ after the injections, and maximum reduction occurs $\sim 2-4$ weeks after treatment. The mean duration of the beneficial effect is usually three and half months, ${ }^{39}$ although the relapse time is extremely variable, and inhibition of saliva production may last up to 6 months after injection. ${ }^{44}$ BoNT serotypes $\mathrm{A}$ and $\mathrm{B}$ are considered to be equally efficacious and safe. In a study evaluating the differences between the 2 serotypes, Guidubaldi et $\mathrm{al}^{46}$ found that BoNT-B has a shorter latency and the same duration of efficacy compared with BoNT-A. However, the costs of the 2 treatments are significantly different: at the doses used in the study, a treatment with BoNT-B costs approximately half that with BoNT-A. In the vast majority of cases, BoNT injection has no side effects. ${ }^{55-57}$ Uncommon adverse events are increased viscosity of saliva, local pain, chewing weakness, and respiratory infections. Anaphylactic reactions are rare but often serious. In $2005, \mathrm{Li}$ et al ${ }^{58}$ reported the first case of death connected with administration of a Botoxlidocaine mixture in a patient with chronic neck and back pain. Another study reported a case of deterioration of bulbar function after botulinum treatment in a patient with ALS. ${ }^{50}$ Four days after injection, the patient suffered rapid onset of bulbar dysfunction, resulting in severe aphagia and anarthria. A progressive cervical kyphosis connected with BoNT injection has also been reported by Hogan et al. ${ }^{56}$

\section{Radiotherapy}

Radiotherapy of the salivary gland has also been proposed as an effective method to reduce excessive drooling in patients with ALS. ${ }^{59}$ Several studies on radiotherapy for the treatment of sialorrhea in ALS adopted different techniques (electron-based therapy vs photon-based therapy) and doses (Table 4). Electron-based therapy appears to be well tolerated and induces a sustained improvement compared with photon-based therapy, with no serious side effects. In a retrospective study by Guy et al, ${ }^{62}$ a good response to radiotherapy was observed in $65 \%$ of subjects. However, 4 of 13 subjects treated with photon-based therapy experienced acute toxicity symptoms (oral pain and mucositis during or immediately after irradiation) or delayed reactions (edema or xerostomia 1 month after irradiation or oral pain 3 months after irradiation). Conversely, none of the 8 subjects treated with electron-based therapy reported side effects. The authors suggested an optimum total dose of $20 \mathrm{~Gy}$ administered in 5 fractions, encompassing the whole of the submandibular gland and sparing the upper part of the parotid gland. The benefits of radiation treatment persisted for 4-6 months. ${ }^{19}$ Another study 


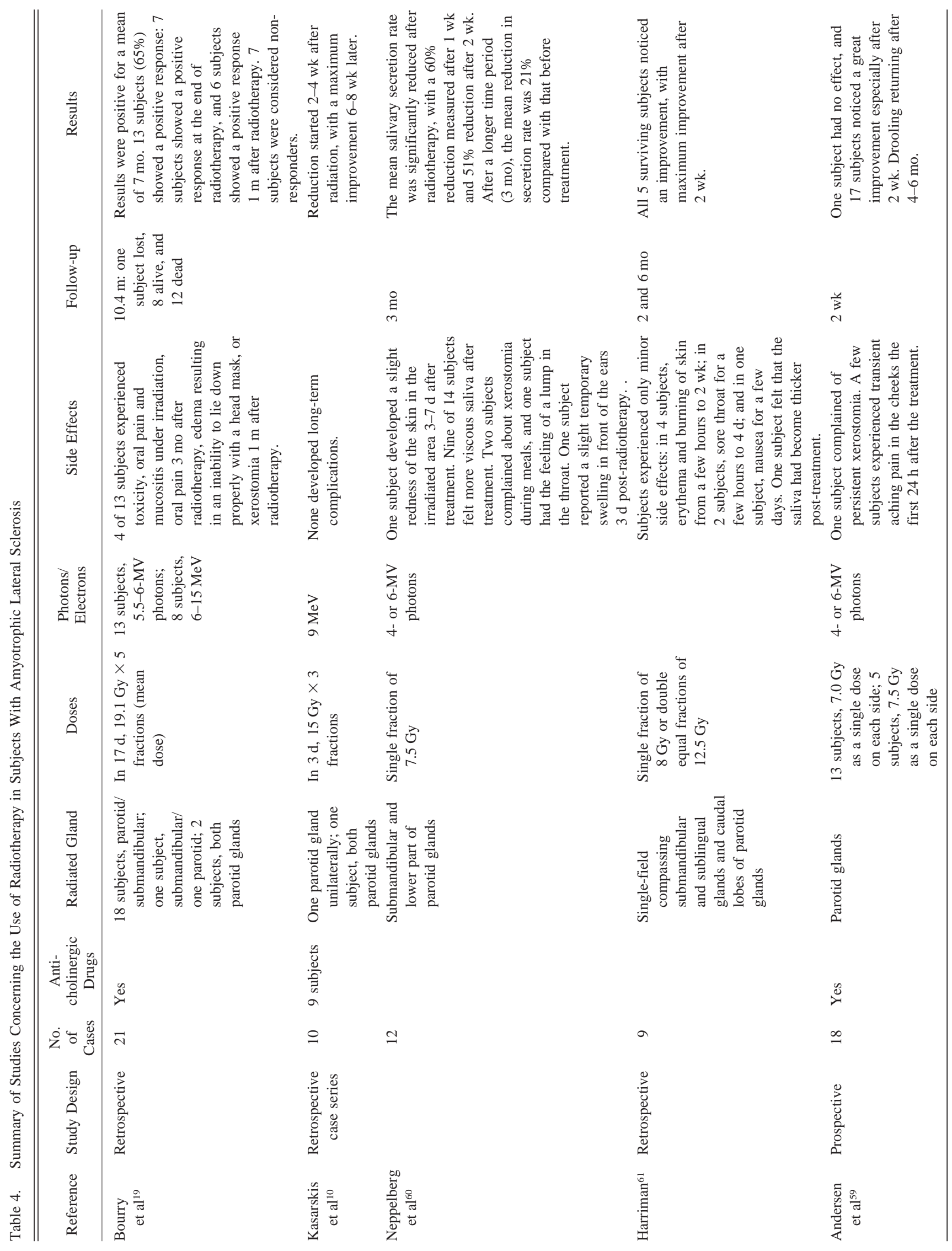




\section{Treatment Options for SialorRhEa IN ALS}

found similar beneficial effects by targeting under computed tomography guidance a single parotid gland unilaterally with a total dose 15 Gy delivered in 3 equal fractions. ${ }^{10}$ Single-dose radiotherapy has also been proven to be beneficial in reducing excessive drooling in ALS. In 14 subjects treated with a single fraction of $7.5 \mathrm{~Gy}$, Neppelberg et al ${ }^{60}$ observed a $50 \%$ reduction in salivary secretion after 2 weeks and a 20\% reduction after 3 months. It has been suggested that a dose of 8 Gy delivered in a single fraction may be as effective and safe as higher fractionated doses, ${ }^{14}$ and increasing the dose did not improve initial achievement. ${ }^{61}$ A review of published studies on BoNT and radiotherapy for sialorrhea in ALS attempted to evaluate and compare the effectiveness and side effects of the 2 treatments. However, because of the small number of published studies, the small sample sizes, and the poor quality of reporting, it was not possible to draw firm conclusions recommending one treatment over the other. ${ }^{42}$

\section{Surgical Treatment}

Another therapeutic option for the management of excessive drooling is surgical intervention. To our knowledge, however, there are no clinical studies focused on patients with ALS in the literature, and most of the published studies were performed on children with cerebral palsy. ${ }^{63}$ In these particular patients, salivary duct or gland surgery is considered to be the best established treatment, especially in the most severe cases of sialorrhea. In 1996, Strauss et al ${ }^{63}$ defined Wilkie's original operation (1967) as "the main surgical procedure" for controlling sialorrhea. The procedure consists of the retropositioning of the parotid ducts into the tonsillar fossa region along with bilateral submandibular gland resection. Several variants of the Wilkie procedure have been described: transposition, instead of resection, of the submandibular gland duct into the tonsillar fossa; ligation, instead of repositioning, of the parotid ducts, along with the usual submandibular gland resection; deviation of both submandibular and parotid ducts behind the anterior pillar of the soft palate (4-duct diversion); bilateral submandibular duct relocation with or without sublingual gland excision; a combination of ipsilateral parotid duct ligation and contralateral parotid duct repositioning; and ligation of both parotid and submandibular ducts (4-duct ligation).

Submandibular duct relocation with or without excision of the sublingual gland is currently the most common approach. By relocating the papillae of the submandibular ducts from the anterior oral cavity to the base of the tongue, saliva from the submandibular glands can flow directly into the oropharynx. ${ }^{64}$ However, this procedure cannot be performed in patients with a history of recurrent aspiration pneumonia, as it may increase aspiration risk because it directs the saliva posteriorly. ${ }^{65}$ The average postoperative stay in a hospital for this kind of procedure is $\sim 2 \mathrm{~d}$. In 2007, Glynn and O'Dwyer66 studied whether the combination of sublingual gland excision and submandibular duct relocation gives better overall results in controlling drooling. They concluded that both procedures were equally effective, but the combination increased the morbidity of the procedure while not providing any better control of drooling. However, this more extensive intervention may prevent ranula formation. ${ }^{66}$

Studies on the efficacy of the 4-duct ligation procedure had contrasting results. In 2008, Stamataki et al ${ }^{67}$ showed that the long-term effectiveness of the 4-duct ligation procedure in controlling anterior drooling is questionable as measured by caregiver satisfaction and need for additional medical and surgical therapies. Martin and Conley 68 reached similar conclusions. However, Chanu et al ${ }^{69}$ obtained very different results. In fact, in their study, 4-duct ligation seemed to be a simple procedure and caused significant reduction in drooling and improved quality of life. Additionally, the procedure had few complications, which could be managed effectively. The authors concluded that 4-duct ligation is effective in controlling moderate-tosevere sialorrhea in children. ${ }^{69}$ Three-duct ligation procedures have also been described in the literature. ${ }^{47}$

Unfortunately, duct ligation is not a permanent solution. In 2006, Osailan et al ${ }^{70,71}$ published 2 works about ligation of the submandibular duct in rats. In the first study, they evaluated submandibular gland atrophy with or without chorda-lingual nerve resection and observed that, in the absence of chorda-lingual ligation, the extent of glandular atrophy was reduced. ${ }^{70}$ In the second study, their goal was to investigate the recovery of submandibular gland function after the removal of an obstruction. ${ }^{71}$ They ligated the submandibular glands of rats with micro-clips for 1,4 , and 8 weeks. The glands were then allowed to recover after removal of the micro-clips for 8,16 , and 26 weeks under stimulation with autonomimetic drugs. The authors concluded that following severe atrophy, the rat submandibular glands regenerated after 24 weeks and secreted normal quantities of saliva. This is true for acinar cells, but not for ductal ones. ${ }^{71}$ In 1989, Grant et al ${ }^{72}$ studied the effect of resection of the chorda tympani nerve on ipsilateral and contralateral salivary secretion. They studied 20 subjects undergoing exploratory ear surgery for mastoidectomy, stapedectomy, or tympanoplasty. Chorda tympani resection did not reduce salivary flow in $35 \%$ of the subjects, whereas in the remaining $65 \%$, the submandibular flow was reduced by $\sim 54 \%$. These results strongly suggest that the morbidity of bilateral chorda tympani section alone outweighs the expected benefit in individuals with sialorrhea and a limited lifespan, such as patients with ALS. Therefore, it can be considered a poor method for reducing stimulated salivary flow. ${ }^{72}$ 


\section{Treatment Options for SialorRhEa IN ALS}

In conclusion, although a surgical approach to sialorrhea is possible in children affected by cerebral palsy, nothing similar has been tested in patients with ALS. Indeed, there is currently no safe and effective surgical therapy for these patients; however, we believe that surgery may represent a valid option for the treatment of excessive drooling in ALS because there is no tachyphylaxis or need for repeated therapeutic sessions.

\section{Conclusions}

In our experience, the first-line treatment for excessive drooling in patients with ALS is represented by anticholinergic medications. Among the different possibilities, we believe the use of a scopolamine transdermal patch $(1.5 \mathrm{mg} / \mathrm{d})$ or sublingual amitriptyline $(25$ drops at bedtime) to be the most effective and best tolerated option. We have no personal experience with glycopyrrolate because it has not been approved for human use in Italy. In non-responders, we also used oxitropium bromide via nasal aerosol (1.5 mg twice daily) with some success. However, anticholinergic drugs are not a definitive solution for excessive drooling in ALS. For this reason, many patients have to deal with other more invasive therapies, such as botulinum injection and radiotherapy. The available data do not permit us to determine with certainty which is the better option. Radiotherapy has fewer side effects but a shorter duration of effect. Conversely, botulinum presents more side effects, but its action lasts longer. To date, there are no evidence-based guidelines for the management of sialorrhea in patients with ALS, and application of the different techniques is based on experience of only a few specialized centers. The goal of this review was to highlight the advantages and disadvantages of each method and to represent a practical tool for all physicians involved in the symptomatic treatment of sialorrhea in ALS.

\section{REFERENCES}

1. Haverkamp LJ, Appel V, Appel SH. Natural history of amyotrophic lateral sclerosis in a database population. Validation of a scoring system and a model for survival prediction. Brain 1995;118(Pt 3): 707-719.

2. Oliver D. The quality of care and symptom control-the effects on the terminal phase of ALS/MND. J Neurol Sci 1996;139 Suppl:134-136.

3. Desport JC, Preux PM, Truong TC, Vallat JM, Sautereau D, Couratier P. Nutritional status is a prognostic factor for survival in ALS patients. Neurology 1999;53(5):1059-1063.

4. Kasarskis EJ, Berryman S, Vanderleest JG, Schneider AR, McClain CJ. Nutritional status of patients with amyotrophic lateral sclerosis: relation to the proximity of death. Am J Clin Nutr 1996;63(1):130137.

5. Silvestre-Rangil J, Silvestre FJ, Puente-Sandoval A, Requeni-Bernal J, Simó-Ruiz JM. Clinical-therapeutic management of drooling: review and update. Med Oral Patol Oral Cir Bucal 2011;16(6):e763e766.
6. Lowe JS, Nigel L. Disorders of movement and system degenerations. In: Graham DI, Lantos PL, editors. Greenfield's neuropathology, 7th edition. London: Hodder Education Publishers; 2002:325430.

7. Strand EA, Miller RM, Yorkston KM, Hillel AD. Management of oral-pharyngeal dysphagia symptoms in amyotrophic lateral sclerosis. Dysphagia 1996;11(2):129-139.

8. Marik PE. Pulmonary aspiration syndromes. Curr Opin Pulm Med 2011;17(3):148-154

9. Young CA, Ellis C, Johnson J, Sathasivam S, Pih N. Treatment for sialorrhea (excessive saliva) in people with motor neuron disease/ amyotrophic lateral sclerosis. Cochrane Database Syst Rev 2011;(5); CD006981.

10. Kasarskis EJ, Hodskins J, St Clair WH. Unilateral parotid electron beam radiotherapy as palliative treatment for sialorrhea in amyotrophic lateral sclerosis. J Neurol Sci 2011;308(1):155-157.

11. Robbins J. Swallowing in ALS and motor neuron disorders. Neurol Clin 1987;5(2):213-229.

12. Newall AR, Orser R, Hunt M. The control of oral secretions in bulbar ALS/MND. J Neurol Sci 1996;139 Suppl:43-44.

13. Hillel A, Dray T, Miller R, Yorkston K, Konikow N, Strande E, Browne J. Presentation of ALS to the otolaryngologist/head and neck surgeon: getting to the neurologist. Neurology 1999;53(8 Suppl 5): S22-S25; discussion S35-S36.

14. Blackhall LJ. Amyotrophic lateral sclerosis and palliative care: where we are, and the road ahead. Muscle Nerve 2012;45(3):311-318.

15. Cedarbaum JM, Stambler N, Malta E, Fuller C, Hilt D, Thurmond B, Nakanishi A. The ALSFRS-R: a revised ALS functional rating scale that incorporates assessments of respiratory function. J Neurol Sci 1999;169(1):13-21.

16. Abdelnour-Mallet M, Tezenas Du Montcel S, Cazzolli PA, Assouline A, Pointon C, Leveque N, et al. Validation of robust tools to measure sialorrhea in amyotrophic lateral sclerosis: a study in a large French cohort. Amyotroph Lateral Scler Frontotemporal Degener 2013;14(4):302-307.

17. Kontis TC, Johns ME. Anatomy and physiology of the salivary glands. In: Bailey BJ, Johnson JT, Newlands SD, editors. Head \& neck surgery-otolaryngology, 4th edition. Philadelphia: Lippincott Williams \& Wilkins; 2006:531-539.

18. Sorenson EJ, Crum B, Stevens JC. Incidence of aspiration pneumonia in ALS in Olmsted County, MN. Amyotroph Lateral Scler 2007; 8(2):87-89.

19. Bourry N, Guy N, Achard JL, Verrelle P, Clavelou P, Lapeyre M. Salivary glands radiotherapy to reduce sialorrhea in amyotrophic lateral sclerosis: dose and energy. Cancer Radiother 2013;17(3):191195.

20. Amin MR, Harris D, Cassel SG, Grimes E, Heiman-Patterson T. Sensory testing in the assessment of laryngeal sensation in patients with amyotrophic lateral sclerosis. Ann Otol Rhinol Laryngol 2006; 115(7):528-534.

21. Hardiman O. Management of respiratory symptoms in ALS. J Neurol 2011;258(3):359-365.

22. Kurian KM, Forbes RB, Colville S, Swingler RJ. Cause of death and clinical grading criteria in a cohort of amyotrophic lateral sclerosis cases undergoing autopsy from the Scottish Motor Neurone Disease Register. J Neurol Neurosurg Psychiatry 2009;80(1):84-87.

23. Cooper-Knock J, Ahmedzai SH, Shaw P. The use of subcutaneous glycopyrrolate in the management of sialorrhoea and facilitating the use of non-invasive ventilation in amyotrophic lateral sclerosis. Amyotroph Lateral Scler 2011;12(6):464-465.

24. Kaplan LM, Hollander D. Respiratory dysfunction in amyotrophic lateral sclerosis. Clin Chest Med 1994;15(4):675-681. 


\section{Treatment Options for SialorRhEa IN ALS}

25. de Carvalho M, Matias T, Coelho F, Evangelista T, Pinto A, Sales Luís ML. Motor neuron disease presenting with respiratory failure. J Neurol Sci 1996;139 Suppl:117-122.

26. Farrero E, Prats E, Povedano M, Martinez-Matos JA, Manresa F, Escarrabill J. Survival in amyotrophic lateral sclerosis with home mechanical ventilation: the impact of systematic respiratory assessment and bulbar involvement. Chest 2005;127(6):2132-2138.

27. Pinto AC, Evangelista T, Carvalho M, Alves MA, Sales Luís ML. Respiratory assistance with a non-invasive ventilator (Bipap) in MND/ ALS patients: survival rates in a controlled trial. J Neurol Sci 1995; 129 Suppl:19-26.

28. Kleopa KA, Sherman M, Neal B, Romano GJ, Heiman-Patterson T. Bipap improves survival and rate of pulmonary function decline in patients with ALS. J Neurol Sci 1999;164(1):82-88.

29. Lyall RA, Donaldson N, Fleming T, Wood C, Newsom-Davis I, Polkey MI, et al. A prospective study of quality of life in ALS patients treated with noninvasive ventilation. Neurology 2001;57(1): 153-156.

30. Bourke SC, Bullock RE, Williams TL, Shaw PJ, Gibson GJ. Noninvasive ventilation in ALS: indications and effect on quality of life. Neurology 2003;61(2):171-177.

31. Sancho J, Servera E, Morelot-Panzini C, Salachas F, Similowski T, Gonzalez-Bermejo J. Non-invasive ventilation effectiveness and the effect of ventilatory mode on survival in ALS patients. Amyotroph Lateral Scler Frontotemporal Degener 2014;15(1-2):55-61.

32. Brooks BR, Lewarski JL, McKim DA, Nakayama Y, Chatburn RL. Oral Secretion Score (OSS) predicts best care interventions and outcomes of patients with ALS/MND using noninvasive ventilation (NIV). Amyotroph Lateral Scler Frontotemporal Degener 2013; 14(Suppl 2):60.

33. Brooks BR, Lewarski JL, McKim DA, Chatburn RL. Oral Secretion Scale (OSS) score in amyotrophic lateral sclerosis patients is associated with tolerance of non-invasive positive pressure ventilation, need for hospice or transition to tracheal positive pressure ventilation (TPPV) and survival (abstract). Amyotroph Lateral Scler 2010; 11(Suppl 1):140.

34. Vandenberghe N, Vallet AE, Petitjean T, Le Cam P, Peysson S, Guérin $\mathrm{C}$, et al. Absence of airway secretion accumulation predicts tolerance to noninvasive ventilation in amyotrophic lateral sclerosis. Respir Care 2013;58(9):1424-1432.

35. Gordon PH, Salachas F, Bruneteau G, Pradat PF, Lacomblez L, Gonzalez-Bermejo J, et al. Improving survival in a large French ALS center cohort. J Neurol 2012;259(9):1788-1792.

36. Jackson CE. Treating the symptoms of amyotrophic lateral sclerosis. In: Mitsumoto H, editor. Amyotrophic lateral sclerosis: a guide for patients and families. New York: Demos Medical Publishing; 2009:53-54.

37. Radunoviæ A, Mitsumoto H, Leigh PN. Clinical care of patients with amyotrophic lateral sclerosis. Lancet Neurol 2007;6(10):913-925.

38. McGeachan AH, Stephenson J, Shaw PJ, McDermott CA. Multicentre evaluation of secretion management in patients with motor neurone disease (MND) (abstract). Amyotroph Lateral Scler Frontotemporal Degener 2013;14(2):59-60.

39. Verma A, Steele J. Botulinum toxin improves sialorrhea and quality of living in bulbar amyotrophic lateral sclerosis. Muscle Nerve 2006; 34(2):235-237.

40. Mato A, Limeres J, Tomás I, Muñoz M, Abuín C, Feijoo JF, Diz P. Management of drooling in disabled patients with scopolamine patches. Br J Clin Pharmacol 2010;69(6):684-688.

41. Jackson CE, Gronseth G, Rosenfeld J, Barohn RJ, Dubinsky R, Simpson CB, et al. Randomized double-blind study of botulinum toxin type B for sialorrhea in ALS patients. Muscle Nerve 2009; 39(2):137-143.
42. Stone CA, O'Leary N. Systematic review of the effectiveness of botulinum toxin or radiotherapy for sialorrhea in patients with amyotrophic lateral sclerosis. J Pain Symptom Manag 2009;37(2):246-258.

43. Gilio F, Iacovelli E, Frasca V, Gabriele M, Giacomelli E, Picchiori $\mathrm{F}$, et al. Botulinum toxin type A for the treatment of sialorrhoea in amyotrophic lateral sclerosis: a clinical and neurophysiological study. Amyotroph Lateral Scler 2010;11(4):359-363.

44. Contarino MF, Pompili M, Tittoto P, Vanacore N, Sabatelli M, Cedrone $\mathrm{A}$, et al. Botulinum toxin $\mathrm{B}$ ultrasound-guided injections for sialorrhea in amyotrophic lateral sclerosis and Parkinson's disease. Parkinsonism Relat Disord 2007;13(5):299-303.

45. Stokholm MG, Bisgård C, Vilholm OJ. Safety and administration of treatment with botulinum neurotoxin for sialorrhoea in ALS patients: review of the literature and a proposal for tailored treatment. Amyotroph Lateral Scler Frontotemporal Degener 2013;14(7-8): 516-520.

46. Guidubaldi A, Fasano A, Ialongo T, Piano C, Pompili M, Mascianà R, et al. Botulinum toxin A versus B in sialorrhea: a prospective, randomized, double-blind, crossover pilot study in patients with amyotrophic lateral sclerosis or Parkinson's disease. Mov Disord 2011;26(2):313319.

47. Anagnostou E, Evangelos A, Rentzos M, Michael R, Alexakis T, Theodoros A, et al. Volume matters: the influence of different botulinum toxin-A dilutions for sialorrhea in amyotrophic lateral sclerosis. Muscle Nerve 2013;47(2):276-278.

48. Costa J, Rocha ML, Ferreira J, Evangelista T, Coelho M, de Carvalho M. Botulinum toxin type-B improves sialorrhea and quality of life in bulbaronset amyotrophic lateral sclerosis. J Neurol 2008; 255(4):545-550.

49. Scott KR, Kothari MJ, Venkatesh YS, Murphy T, Simmons Z. Parotid gland injections of botulinum toxin a are effective in treating sialorrhea in amyotrophic lateral sclerosis. J Clin Neuromuscul Dis 2005;7(2):62-65.

50. Giess R, Naumann M, Werner E, Riemann R, Beck M, Puls I, et al. Injections of botulinum toxin $\mathrm{A}$ into the salivary glands improve sialorrhoea in amyotrophic lateral sclerosis. J Neurol Neurosurg Psychiatry 2000;69(1):121-123.

51. Møller E, Karlsborg M, Bardow A, Lykkeaa J, Nissen FH, Bakke M. Treatment of severe drooling with botulinum toxin in amyotrophic lateral sclerosis and Parkinson's disease: efficacy and possible mechanisms. Acta Odontol Scand 2011;69(3):151-157.

52. Manrique D. Application of botulinum toxin to reduce the saliva in patients with amyotrophic lateral sclerosis. Braz J Otorhinolaryngol 2005;71(5):566-569.

53. Lipp A, Trottenberg T, Schink T, Kupsch A, Arnold G. A randomized trial of botulinum toxin A for treatment of drooling. Neurology 2003;61(9):1279-1281.

54. Porta M, Gamba M, Bertacchi G, Vaj P. Treatment of sialorrhoea with ultrasound guided botulinum toxin type $\mathrm{A}$ injection in patients with neurological disorders. J Neurol Neurosurg Psychiatry 2001; 70(4):538-540.

55. Meijer JW, van Kuijk AA, Geurts AC, Schelhaas HJ, Zwarts MJ. Acute deterioration of bulbar function after botulinum toxin treatment for sialorrhoea in amyotrophic lateral sclerosis. Am J Phys Med Rehabil 2008;87(4):321-324.

56. Hogan KA, Manning EL, Glaser JA. Progressive cervical kyphosis associated with botulinum toxin injection. Southern Med J 2006; 99(8):888-891.

57. Restivo DA, Casabona A, Nicotra A, Zappia M, Elia M, Romano MC, et al. ALS dysphagia pathophysiology: differential botulinum toxin response. Neurology 2013;80(7):616-620.

58. Li M, Goldberger BA, Hopkins C. Fatal case of BOTOX-related anaphylaxis? J Forensic Sci 2005;50(1):169-172. 


\section{Treatment Options for SialorRhEa IN ALS}

59. Andersen PM, Grönberg H, Franzen L, Funegård U. External radiation of the parotid glands significantly reduces drooling in patients with motor neurone disease with bulbar paresis. J Neurol Sci 2001; 191(1-2):111-114.

60. Neppelberg E, Haugen DF, Thorsen L, Tysnes OB. Radiotherapy reduces sialorrhea in amyotrophic lateral sclerosis. Eur J Neurol 2007;14(12):1373-1377.

61. Harriman M, Morrison M, Hay J, Revonta M, Eisen A, Lentle B. Use of radiotherapy for control of sialorrhea in patients with amyotrophic lateral sclerosis. J Otolaryngol 2001;30(4):242-245.

62. Guy N, Bourry N, Dallel R, Dualé C, Verrelle P, Lapeyre M, Clavelou P. Comparison of radiotherapy types in the treatment of sialorrhea in amyotrophic lateral sclerosis. J Palliat Med 2011;14(4): 391-395.

63. Strauss M, Nageris B, Shvili Y, Feinmesser R. The surgical management of drooling. Oper Tech Otolaryngol Head Neck Surg 1996; 7(4):311-314.

64. Ethunandan M, Macpherson DW. Persistent drooling: treatment by bilateral submandibular duct transposition and simultaneous sublingual gland excision. Ann R Coll Surg Engl 1998;80(4):279-282.

65. Puraviappan P, Dass DB, Narayanan P. Efficacy of relocation of submandibular duct in cerebral palsy patients with drooling. Asian J Surg 2007;30(3):209-215.
66. Glynn F, O'Dwyer TP. Does the addition of sublingual gland excision to submandibular duct relocation give better overall results in drooling control? Clin Otolaryngol 2007;32(2):103-107.

67. Stamataki S, Behar P, Brodsky L. Surgical management of drooling: clinical and caregiver satisfaction outcomes. Int J Pediatr Otorhinolaryngol 2008;72(12):1801-1805.

68. Martin TJ, Conley SF. Long-term efficacy of intra-oral surgery for sialorrhea. Otolaryngol Head Neck Surg 2007;137(1):54-58.

69. Chanu NP, Sahni JK, Aneja S, Naglot S. Four-duct ligation in children with drooling. Am J Otolaryngol 2012;33(5):604-607.

70. Osailan SM, Proctor GB, McGurk M, Paterson KL. Intraoral duct ligation without inclusion of the parasympathetic nerve supply induces rat submandibular gland atrophy. Int J Exp Pathol 2006;87(1): 41-48.

71. Osailan SM, Proctor GB, Carpenter GH, Paterson KL, McGurk M. Recovery of rat submandibular salivary gland function following removal of obstruction: a sialometrical and sialochemical study. Int J Exp Pathol 2006;87(6):411-423.

72. Grant R, Miller S, Simpson D, Lamey PJ, Bone I. The effect of chorda tympani section on ipsilateral and contralateral salivary secretion and taste in man. J Neurol Neurosurg Psychiatry 1989;52(9): 1058-1062. 